\title{
23: Summary of Risks
}

This Chapter has been intended to catalogue the risks. Risk assessment is a complicated business which is unfortunately often left to relatively junior staff to assess. This happens because it is time-consuming and sometimes considered menial. While it is excellent training for new staff, risk assessment is best done in teams, either formally or informally with senior and junior staff both involved.

The process of analysing risk can be so absorbing to those involved in it that it becomes an end in itself. There is little point in this unless the function of the organisation is the provision of risk analysis to clients. For export finance houses and banks the goal should be to fully understand the risks at stake with a view to doing safe business.

Many banks, however, see their role as finding reasons for not doing business. This, fortunately is becoming less prevalent as competition among banks and the pressure to reduce costs and up shareholder returns becomes more intense.

The goal then of risk analysis is to arrive at a position where the export financier can say:

- 'I have analysed this piece of business and understand all of the risks bearing upon it';

- 'I have structured the deal so as to minimise these risks'; or

- 'it is now sufficiently tightly arranged that we can carry it out profitably without undue risk to the firm'. 